\title{
Sponge-derived natural bioactive glass microspheres with self-assembled surface channel arrays opening into a hollow core for bone tissue and controlled drug release applications
}

Murat Kaya $^{\mathrm{a}, *}$, Ismail Bilican ${ }^{\mathrm{b}, \mathrm{c}}$, Muhammad Mujtaba ${ }^{\mathrm{d}}$, Idris Sargin ${ }^{\mathrm{e}}$, Merve Erginer Haskoylu ${ }^{\mathrm{f}}$, Ebru Toksoy Oner ${ }^{\mathrm{f}}$, Kai Zheng ${ }^{\mathrm{g}}$, Aldo R. Boccaccini ${ }^{\mathrm{g}}$, Demet Cansaran-Duman ${ }^{\mathrm{d}}$, M. Serdar Onses ${ }^{\mathrm{h}, \mathrm{i}}$, Ilker Torun ${ }^{\mathrm{h}, \mathrm{i}}$, Lalehan Akyuz ${ }^{\mathrm{j}}$, Caglar Elbuken ${ }^{\mathrm{c}, \mathrm{k}}$, Martin Vinther Sørensen ${ }^{1}$

${ }^{a}$ Department of Biotechnology and Molecular Biology, Faculty of Science and Letters, Aksaray University, 68100 Aksaray, Turkey

${ }^{\mathrm{b}}$ Department of Electronics and Automation, Technical Vocational School, Aksaray University, 68100 Aksaray, Turkey

${ }^{\mathrm{c}}$ UNAM -National Nanotechnology Research Center, Institute of Materials Science and Nanotechnology, Bilkent University, 06800 Ankara, Turkey

${ }^{\mathrm{d}}$ Institute of Biotechnology, Ankara University, 06110 Ankara, Turkey

e Selcuk University, Faculty of Science, Department of Biochemistry, 42075 Konya, Turkey

${ }^{\mathrm{f}}$ Department of Bioengineering, Faculty of Engineering, Marmara University, 34722 Istanbul, Turkey

${ }^{\mathrm{g}}$ Institute of Biomaterials, University of Erlangen-Nuremberg, 91058 Erlangen, Germany

${ }^{\mathrm{h}}$ ERNAM - Erciyes University Nanotechnology Application and Research Center, 38039 Kayseri, Turkey

${ }^{\mathrm{i}}$ Department of Materials Science and Engineering, Erciyes University, Kayseri 38039, Turkey

${ }^{\mathrm{j}}$ Department of Chemistry Technology, Technical Vocational School, Aksaray University, 68100 Aksaray, Turkey

${ }^{\mathrm{k}}$ Faculty of Biochemistry and Molecular Medicine, Faculty of Medicine, University of Oulu, 90014 Oulu, Finland

${ }^{1}$ Natural History Museum of Denmark, University of Copenhagen, DK-2100 Copenhagen, Denmark

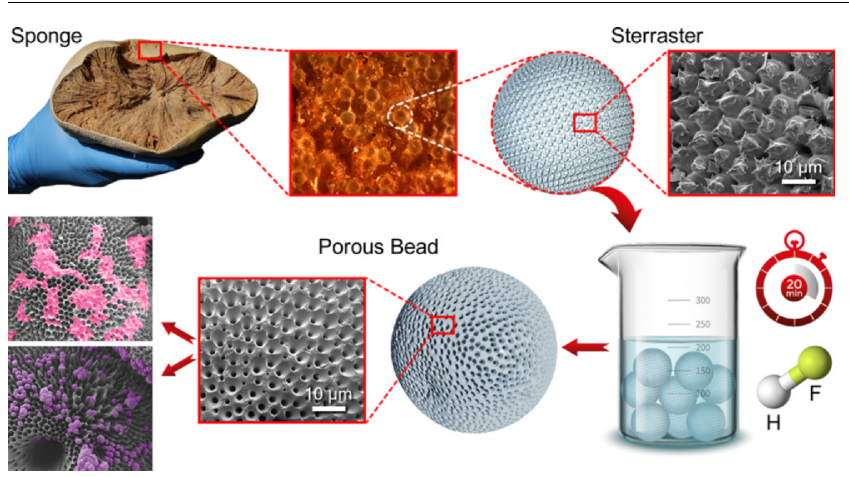

\section{A R T I C L E I N F O}

\section{Keywords:}

Biosilica

Porous beads

Macroporous silica

Bone tissue

Drug release

Porifera

\begin{abstract}
A B S T R A C T
Porous, bioactive microspheres have always been a dream material to biomedical scientists for bone regeneration and drug delivery applications due to their interconnectivity, unique pore geometry, encapsulation ability and porosity spanning macroscopic, microscopic and nanoscopic length scales. Extensive efforts have been made to produce such materials synthetically at a great cost of money, time and labor. Herein, naturallyassembled multifunctional, open-channeled and hollow bioactive micro silica spheres (diameter $209.4 \pm 38.5 \mu \mathrm{m}$ ) were discovered in a marine sponge (Geodia macandrewii), by peeling the outer surface of the sterrasters using hydrogen fluoride. The obtained micro silica spheres exhibited valuable characteristics such as
\end{abstract}

\footnotetext{
* Corresponding author.

E-mail address: muratkaya3806@yahoo.com (M. Kaya).
} 
Geodia

Sterrasters homogeneously distributed pores, a cavity in the center of the sphere, and channels (approx. 3000) opening from each pore into the central cavity. Simulated body fluid analysis demonstrated the bioactivity of the micro silica spheres; whereas, no bioactivity was recorded for the original untreated sterrasters. The non-cytotoxicity and osteogenic ability of the isolated microspheres were confirmed through osteoblast cell culture. Finally, these silica based porous microspheres were tested for controlled drug release capacity. The spheres showed excellent loading and release abilities for an anti-cancer drug, carboplatin, in simulated solutions and in human cancer cell culture, HeLa, through a real time cell analyzer system. The drug loading capacity of the porous beads was determined as $10.59 \%$. Considering the unique biological and physicochemical properties, these novel bioactive silica spheres, which we name as giant macroporous silica (GMS), are promising materials for a range of applications including bone tissue engineering and drug delivery.

\section{Introduction}

Natural porous sphere-like structures are desired for biomedical applications especially in bone tissue engineering and drug delivery due to their interconnectivity, unique pore geometry, encapsulation ability, macro/micro/nano porosity. The motives for selecting the bioactive porous spheres for such applications are their ability to i) accelerate in vivo cell adhesion, and biological fixation via the extended surface area, ii) facilitate ion release, iii) increase adsorption, iv) enable mineral deposition and v) and tunable release of cargo [1]. Therefore, bioactive composite spheres consisting of metals, calcium phosphate, ceramics and polymers have been fabricated and successfully applied for bone tissue engineering and drug delivery [2-10]. Intensive efforts in terms of money, time and labor, are underway to synthetically construct microsphere-like materials with desired properties including, suitable pore geometry, size homogeneity and mechanical properties. In this regard, the search for inexpensive and natural materials as an alternative to synthetic materials is required.

Biosilica is gaining huge attention in terms of its applications in biomedical science thanks to its natural, biocompatible and osteogenesis inductive properties $[11,12]$. Synthetic shaping and modification of silica require high temperature and pressure, harsh acidic or alkaline treatments and large amounts of energy. On the other hand, living organisms produce silica free of cost with excellent geometrical structures under ambient conditions in terms of temperature, $\mathrm{pH}$ and pressure. Silica is present in a variety of terrestrial and aquatic organisms including diatoms, sponges, radiolarians, choanoflagellates and higher plants. According to an estimate, the terrestrial and aquatic organisms process approximately 6.7 gigatons of biosilica every year for building their silica-rich skeletons. This considerable amount of natural biosilica produced by such organisms is a promising low-cost alternative to synthetic silica industry.

Silica-rich sponge spicules exist in different shapes such as sterrasters, selenasters, monaxons, triaxons, tetraxons and polyaxons [13]. Considering the literature reports regarding sponge spicules, a large number of studies have mainly focused on the larger megascleres, in terms of development, structural definition and biomedical applications [14-18]. However, another siliceous skeletal element is the much

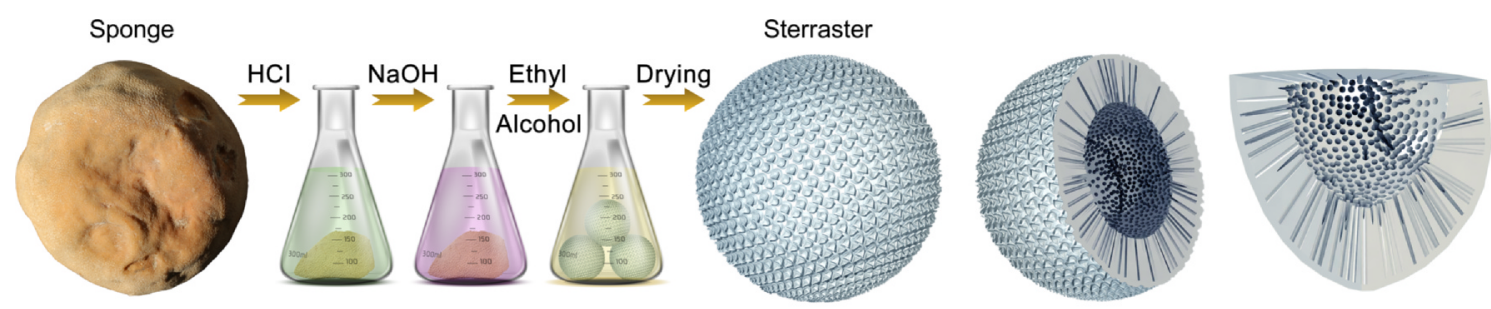

Step 1: Sterraster isolation from sponge
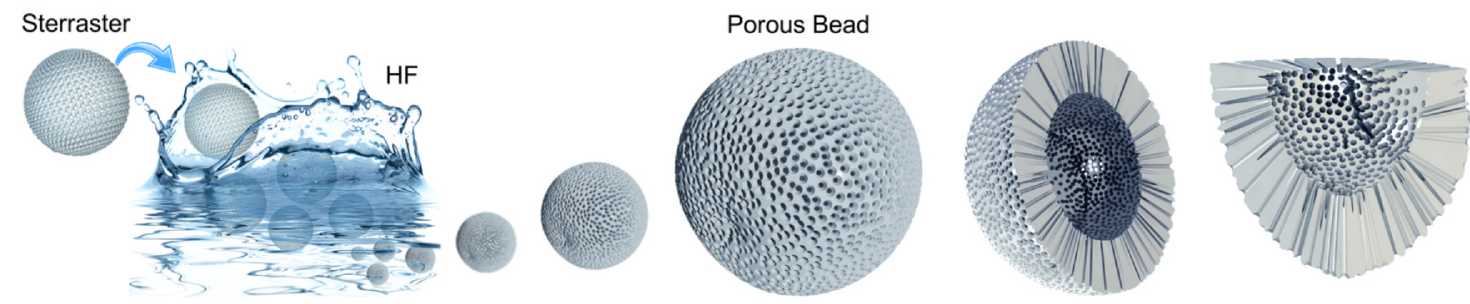

Step 2: Porous microbeads production
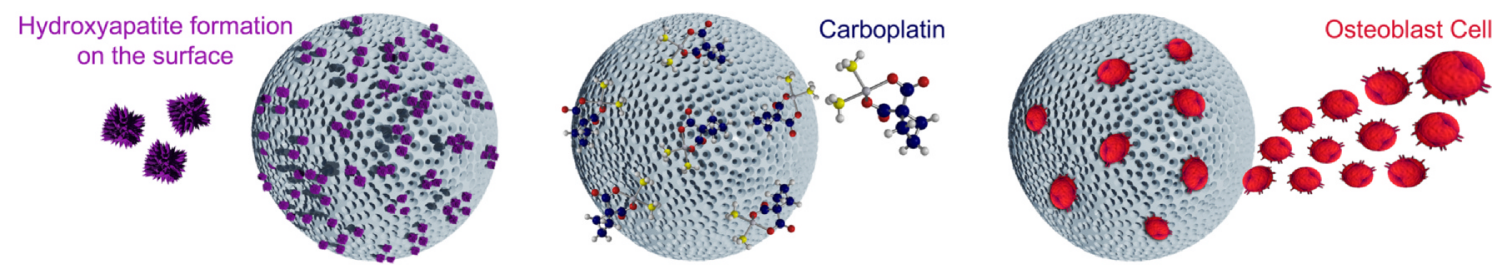

Step 3: Applications of porous microbeads

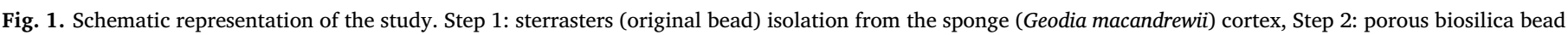

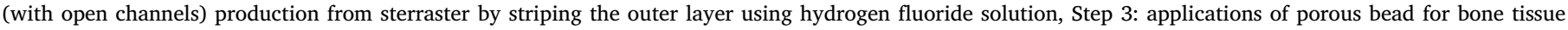
engineering and drug release: Hydroxyapatite formation on the porous beads, Carboplatin loading, osteoblast cell attachment. 
smaller microscleres. Species of the marine demosponge genus Geodia, are large globular or dish-shaped organisms, with an inner subcortical tissue packed with acicular megascleres, and on the outside a leatherlike cortex composed of microscleres. The main component of this cortex is a layer of densely packed oval-shaped microscleres known as sterrasters (Figs. 1 and 2). So far, these sterrasters have only been described from taxonomical and morphological aspects [19-22]; however, no study has described the spheroid structures from a material perspective. Herein, the sterrasters of the North Atlantic deep-sea sponge Geodia macandrewii were examined from a material perspective. The species is a fairly large, spherical or subspherical sponge, with a white or beige cortex, and shows close resemblance to another, even more common North Atlantic species, Geodia barretti. Geodia macandrewii is known from Norway, Great Britain, the Faroe Islands, Iceland, Greenland, Newfoundland and off the northeast US coast, and is typically found from $150 \mathrm{~m}$ down to more than $2000 \mathrm{~m}$ depth [23,24]. For the present study, a new protocol has been developed for peeling the outer layer of the sterrasters that allowed the discovery of the naturallyassembled multifunctional, open-channel and hollow bioactive micro silica spheres. Due their resemblance to the mesoporous silica nanoparticles, we name these beads as giant macroporous silica (GMS) particles. The porous biosilica beads were characterized using various analytical tools. The bioactivity test in simulated body fluid (SBF) was done and its utility for bone tissue engineering was investigated.
Furthermore, cytotoxicity tests were performed. In vitro and semi in vivo drug release tests were carried out to check the control release ability of the porous biosilica beads.

\section{Material and methods}

\subsection{Material}

Specimens of G. macandrewii were provided from the collections of the Natural History Museum of Denmark, and included six specimens from the Faroe Islands collected in 1988, and a single, very large specimen from East Greenland, collected in 1994 (catalogue numbers NHMD-300178, NHMD-300181, and NHMD-303291).

Ethanol was purchased from Merck Inc. Tridecafluoro-1,1,2,2-tetrahydrooctyl-trichlorosilane and dodecyltrichlorosilane were purchased from Gelest Inc. Toluene, sodium hydroxide, hydrochloric acid and silica nanoparticles (average diameter of $13 \mathrm{~nm}$ ) were purchased from Sigma-Aldrich Inc.

\subsection{Isolation and modification of sponge sterrasters from the shells}

\subsubsection{Demineralization by acid hydrolysis}

Due to the high abundance of sterrasters in the cortex of the sponge, the isolation process was made only from the cortex. To remove the
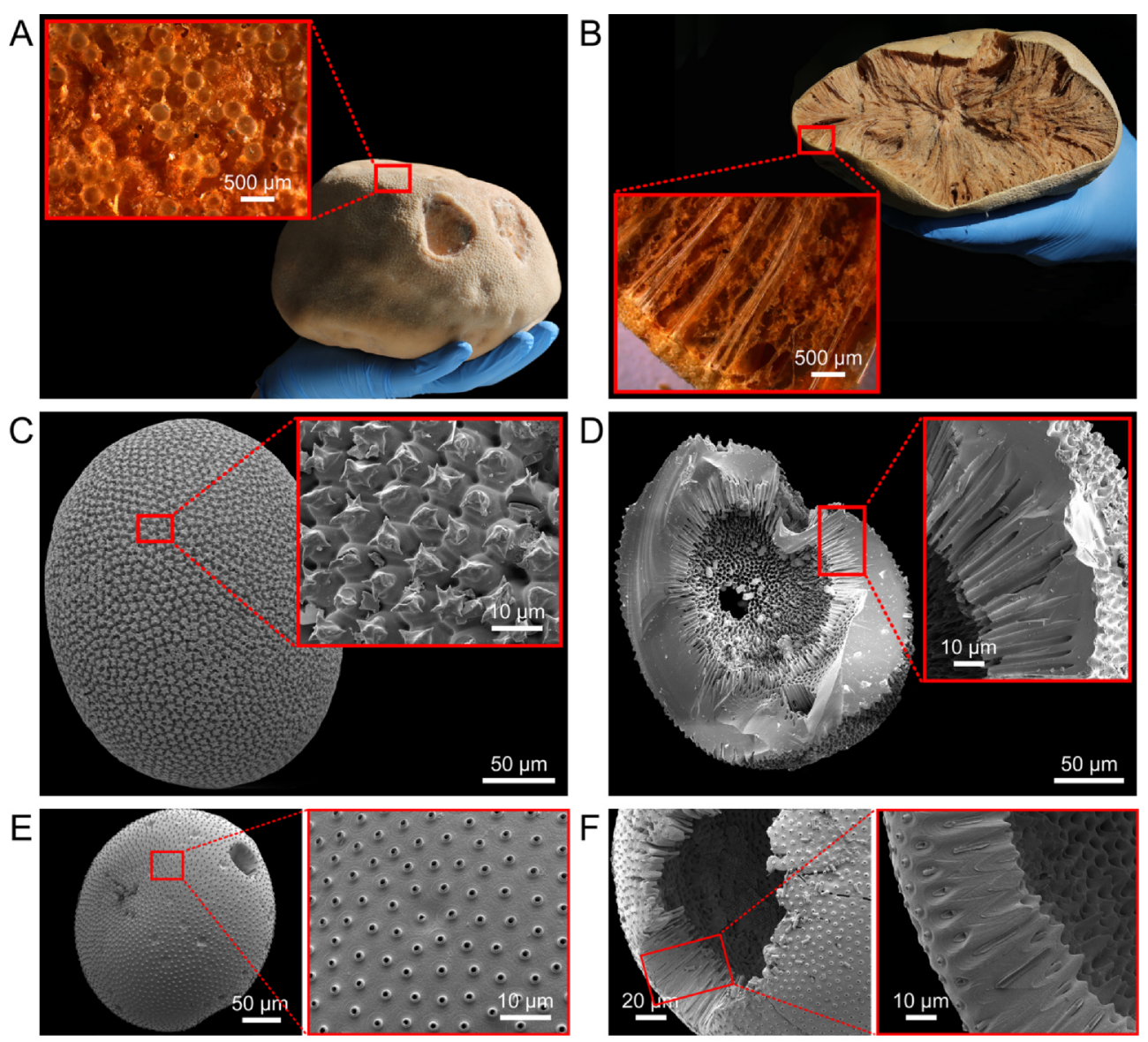

$G$

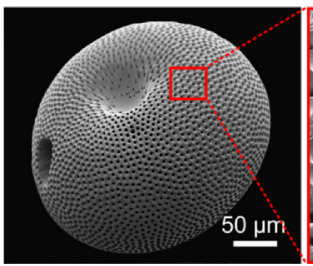

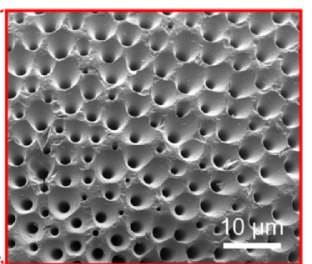

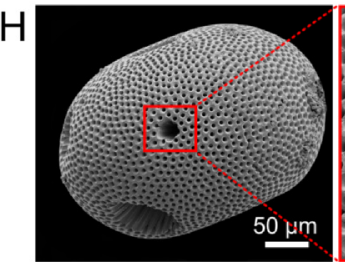

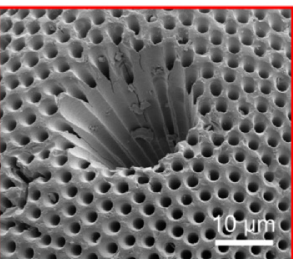

Fig. 2. Sterraster (original bead) isolation from the sponge and then production of porous biosilica beads. (A) The species (Geodia macandrewii) of sponge used in the study and sterrasters on it. (B) a section inward from the outer shell of the sponge. (C) SEM images of the sterrasters. (D) Showing the gap in the center of the sterrasters and the channels. As is seen, the channels are not opening to the outside. (E) and (F) after soft hydrogen fluoride treatment. The channels are opening to the cavity core. (G) and (F) The porous biosilica beads after standard hydrogen fluoride treatment. All the channels are clearly opening to a void in the center of the bead. 
non-silicate minerals and other similar residues found in the structure of the sponges, the samples were treated with $\mathrm{HCl}(2 \mathrm{M})$ aqueous solution at room temperature for $2 \mathrm{~h}$. Then the acid-treated sponge samples were subjected to an intensive washing with distilled water using Whatman filter paper until it reached neutral $\mathrm{pH}$. In this step, minerals and other similar residues were removed from the sponge samples.

\subsubsection{Removal of protein and similar structures by base hydrolysis}

The samples were treated with a $\mathrm{NaOH}(2 \mathrm{M})$ aqueous solution in a reflux system at $100{ }^{\circ} \mathrm{C}$ for $2 \mathrm{~h}$. Subsequently, it was washed with distilled water until it reached the neutral $\mathrm{pH}$. Base hydrolysis ensured the removal of proteins and other similar residues from the sponge structure.

\subsubsection{Depigmentation by alcohol treatment}

For decolorization and depigmentation the sponge samples were treated with $10 \%$ ethyl alcohol solution for $1 \mathrm{~h}$ at room temperature to remove the pigments and then washed with distilled water until they reached the neutral $\mathrm{pH}$. Any pigment or similar structures that may have remained on the surface of the obtained glass beads were removed.

After all these treatments, biosilica fibers and sterraster structures were obtained. When the samples were repeatedly rolled along a surface of a piece of paper, the fiber biosilica samples remained on the paper while the sterraster structures moved onto the other side of the paper due to their oval shape. In this way, sterrasters were obtained in high purity (Fig. S1, Supporting Information).

\subsection{Abrasion of the upper layers of sterrasters with hydrofluoric acid solution}

In this highly important part of the study, the freshly produced sterrasters were treated with varying concentrations of hydrofluoric acid (HF) solutions. The HF treatment resulted in concentration-dependent surface abrasions of the glass beads leading to the production of porous micro glass spheres with the desired surface geometry. Briefly, glass beads $(50 \mathrm{mg})$ were treated in $0.5 \mathrm{~mL} \mathrm{HF}$ solutions (v/v) $(2 \%, 5 \%, 10 \%, 20 \%, 30 \%, 40 \%$ and $50 \%)$ for $20 \mathrm{~min}$ at room temperature and then washed with distilled water until they reached the neutral $\mathrm{pH}$. Then the samples were dried by slowly heating from 25 to $100{ }^{\circ} \mathrm{C}$. Among all the tested concentrations of $\mathrm{HF}(2 \%, 5 \%, 10 \%, 20 \%$, $30 \%, 40 \%$ and $50 \%$ ), the production of the desired porous microspheres was best achieved at $20-40 \%$. At lower concentrations, the same results can be obtained by extending the time of HF treatment. Even in operational conditions (high temperature, the addition of a catalyst, microwave irradiation, etc.), the desired material can be produced. Also, the initial amount of bioglass beads is of immense importance for the successful isolation of porous bioglass microspheres.

\subsection{Characterization of sterrasters and porous beads}

IR spectra of porous beads obtained from $G$. macandrewii were recorded using FT-IR in the wavelength range of $4000-650 \mathrm{~cm}^{-1}$ (Perkin Elmer Spectrum, USA). Thermogravimetric analysis of original beads and porous beads was carried out under nitrogen atmosphere at a heating rate of $10^{\circ} \mathrm{C} / \mathrm{min}$ in range of $30-900{ }^{\circ} \mathrm{C}$ (Exstar-TG/DTA 7300). The X-Ray Diffraction (Bruker AXS D8 Advance) analyses of the original and porous beads samples were made at $2 \theta$ in the range of $10-60^{\circ}$ scan angle at $40 \mathrm{kV}$ and $30 \mathrm{~mA}$. The surface morphologies of the samples were obtained using Scanning Electron Microscopy (FEI-Quanta FEG 250). Energy dispersion spectrum was obtained at $20 \mathrm{kV}$ and $5.000 \times$ magnification (EDAX-Octane Pro).

The water contact angle measurements were performed using a custom setup, which consists of a motorized $\mathrm{x}$-y stage, a needle holder placed on a manual z-stage, a magnification lens (VZM 1000i), and a high-speed camera (2068 FPS, Attention Theta Lite). A stainless-steel needle with an inner diameter of $60 \mu \mathrm{m}$ was used to deposit water droplets $(0.2 \mu \mathrm{L})$. The water contact angles were calculated by analysis of the captured images in ImageJ software.

\subsection{In vitro bioactivity test}

In vitro bioactivity of original and porous beads was assessed following a protocol proposed by Kokubo and Takadama [25]. Briefly, the beads were soaked in $\mathrm{SBF}(1 \mathrm{mg} / \mathrm{mL})$ and kept in an incubator (KS 4000i control, IKA, Germany) at $37^{\circ} \mathrm{C}$ shaking at $90 \mathrm{rpm}$ for up to 21 days. At predetermined time points, the beads were collected by filtration and rinsed with deionized water and acetone before drying at $60{ }^{\circ} \mathrm{C}$ overnight. The surface morphology of the beads after soaking in SBF was characterized using field emission scanning electron microscope (FE-SEM; Auriga, Zeiss, Germany). The SEM images were taken at an acceleration voltage of $2 \mathrm{kV}$. The chemical composition of the beads was analyzed using energy dispersive spectroscopy (EDS, X-Max ${ }^{\mathrm{N}} \mathrm{Ox}$ ford Instruments, UK) at an acceleration voltage of $15 \mathrm{kV}$ and a working distance of $6 \mathrm{~mm}$. Fourier transform infrared spectroscopy (FT-IR) was performed in transmission mode under ambient condition by using IRAffinity-1S (Shimadzu, Japan) spectrophotometer. The samples and $\mathrm{KBr}$ were mixed at a ratio of 1:100 (wt\%) and pressed to pellets for FTIR measurements. The spectra were collected in the region from 400 to $1200 \mathrm{~cm}^{-1}$ with a resolution of $4 \mathrm{~cm}^{-1}$. Powder X-ray diffraction (XRD) was performed using a Philips X'pert diffractometer (Philips, Netherlands) in $2 \theta$ range of $20-80^{\circ}$ with $\mathrm{Cu} \mathrm{K} \alpha$ radiation. A step size of $0.020^{\circ}$ with a dwelling time of $1 \mathrm{~s}$ per step was applied.

\subsection{Cell culture applications}

To analyze biocompatibility of sterrasters and porous biosilica beads, in-vitro WST-1 (4-[3-(4-iodophenyl)-2-(4-nitrophenyl)-2H-5-tetrazolio]-1,3-benzenedisulfonate), (Roche Applied Science, Germany) cell proliferation and viability assay was performed with human osteoblast (HOB) cell line. Sterrasters and porous beads were sterilized with UV for $30 \mathrm{~min}$ followed by autoclave sterilization for $3 \mathrm{~min}$. HOB cells at the $70 \%$ confluency were seeded into 6 well plates onto sterilized sterrasters and porous beads at the density of $5 \times 10^{5}$ and incubated for 24,48 and $72 \mathrm{~h}$ at $37^{\circ} \mathrm{C}, 5 \% \mathrm{CO}_{2}$ humidified incubator. Following the initial incubation, WST-1 cell proliferation reagent was added and incubated 2 more hours at dark and absorbance was measured at $450 \mathrm{~nm}$ by Multimode plate reader (GloMax Multi + Microplate Multimode Reader, Promega, USA). Untreated cells, which contain no bioglass, were considered as $100 \%$ viable.

\subsubsection{Cell attachment on bioglass beads}

Osteoblast cell attachment and proliferation on sterrasters and porous beads were further investigated via fluorescence microscopy and SEM imaging. Sterrasters and porous beads that had been incubated with cells for 24,48 and $72 \mathrm{~h}$ were washed with phosphatebuffered saline (PBS) and fixed with $4 \%$ paraformaldehyde in PBS solution. For fluorescence microscopy images, the fixed samples were stained with DAPI (4', 6-diamidino-2-phenylindole, AppliChem, Germany) and kept in dark. After fixation both samples for SEM and fluorescence microscopy were dehydrated with increasing ethanol concentrations (70, 80, 90 and 100\%) and air-dried before the analyses.

\subsubsection{Statistical analyses}

Statistical analyses of the results were performed with Graph Pad Prism 5. One-Way Anova and Tukey tests were performed to estimate the significance of samples with $95 \%$ confidence interval (CI). All experiments were performed in triplicates.

Drug loading and releasing procedures can be found in the Supporting Information. 


\section{Results}

A general outline of the study is schematized in Fig. 1. Sterrasters (original beads) were isolated from the $G$. macandrewii after $\mathrm{HCl}, \mathrm{NaOH}$ and ethyl alcohol treatments. Then, the outer surface of the isolated original beads structures was etched with HF solution and porous micro bead structures, GMS, were revealed. It was determined that the porous biosilica beads are bioactive and form hydroxyapatite when they come into contact with body fluids. It has been demonstrated that Carboplatin, a cancer drug [26], can be loaded into the beads and the osteoblast cells attach on their surface, which indicates non-toxicity.

\subsection{Production and characterization of sterrasters and porous beads}

In this study, porous micro glass beads were produced by a chemical modification process from sterraster structures of $G$. macandrewii belonging to the family Geodiidae. Stereo microscopy images of the sponge from different parts (outer surface and a section taken from the outside inward) show that the sterraster structures are densely located in the outer cortex (Fig. 2A and B). Original bead structures have external protrusions (Fig. 2C) and underneath these protrusions, there are channels opening towards the central cavity (Fig. 2D). As a result of the soft HF treatment $(5-10 \% \mathrm{v} / \mathrm{v})$, the tube-shaped channels became visible by stripping the protrusions on the surface and the outer layer
(Fig. 2E). All channels (approx. 3000) open into the central cavity independently without touching each other (Fig. 2F). As a result of HF treatment $(20-40 \% \mathrm{v} / \mathrm{v})$, the tube shaped channels on the surface completely eroded away, and opened to the center cavity through channels (Fig. 2G and H). The diameters of the porous beads are $209.4 \pm 38.5 \mu \mathrm{m}$ and the diameters of the pores (channels) on the surface of the beads are $2.3 \pm 1.1 \mu \mathrm{m}$. More photos related to the porous biosilica beads are provided in Figs. S2-S5 (Supporting Information).

The FT-IR analysis showed that the whole structure of the beads consisted of Si-O bonds (Fig. 3). In the FT-IR spectrum, the peak at the $805.43 \mathrm{~cm}^{-1}$ corresponds to the $\mathrm{Si}-\mathrm{O}$ bending vibration. The sharp peak observed at the $1090.1 \mathrm{~cm}^{-1}$ is associated with the characteristic peak of silicon oxide compounds assigned to the Si-O-Si stretching vibrations. Silicon-oxygen linkages have previously been discussed by Greeley, Meeuwenberg [27] using FT-IR analysis. FT-IR results clearly proved the biosilica beads consisted of $\mathrm{SiO}_{2}$. The thermal stability of original and porous beads is shown in Fig. 3B. For both samples, a 4\% mass loss occurred between 30 and $120^{\circ} \mathrm{C}$, which was attributed to evaporation of water. 5.88 and $6.91 \%$ mass losses for original and porous beads were recorded between 120 and $900{ }^{\circ} \mathrm{C}$ due to the degradation of residue organic matter on the beads. The thermal analysis results of the biosilica samples are in agreement with previously reported data [28]. For XRD analysis of both the original and porous bead

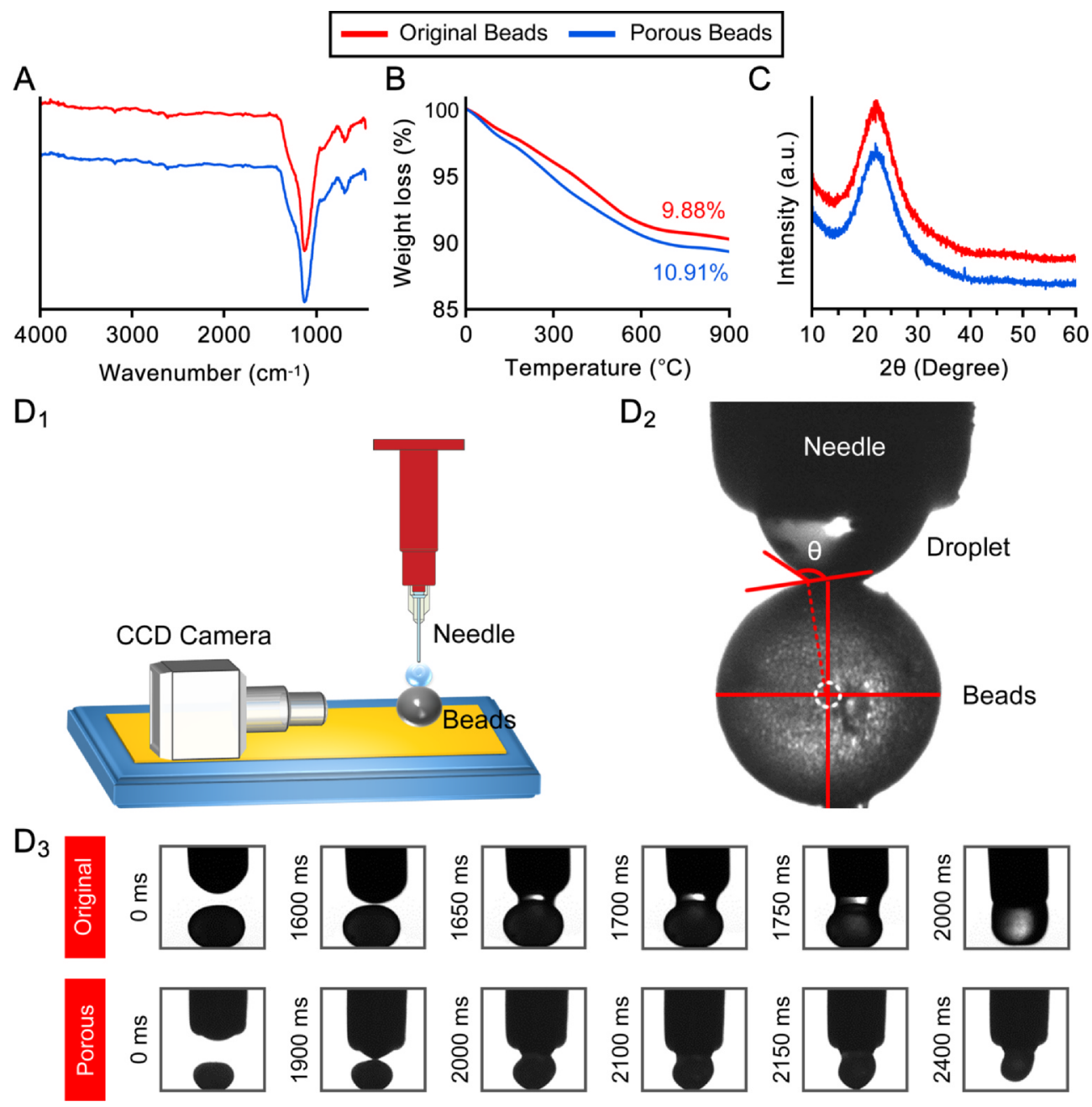

Fig. 3. (A) FT-IR spectrum of original and porous beads. (B) TG results of original and porous beads, (C) XRD results of original and porous beads. ( $\mathrm{D}_{1}$ - $\mathrm{D}_{3}$ ) Surface wetting characteristics of the beads. $\left(D_{1}\right)$ Schematic of the custom setup used in the measurement of water contact angles of the bead. The inset shows a photo of the setup. $\left(D_{2}\right)$ A representative image of a bead and a water droplet. The water contact angle $\left(158.2^{\circ} \pm 5^{\circ}\right)$ is shown on the image. $\left(D_{3}\right)$ High speed camera images during the approach of a water droplet to the original and porous bead. On the left, time of the image captured is presented. 
samples, a wide peak specific to natural amorphous biosilica was observed between 16 and $35^{\circ}$ at $2 \theta$ (Fig. 3C). The absence of other peaks in the diffractogram indicates the high purity of the biosilica samples [29].

The relatively small size of the beads and their non-planar nature challenge measurement of water contact angles using conventional setups. Hence, in this study, a custom setup was designed that consists of a motorized stage and a camera (Fig. 3D1) for pendant drop measurement. The surface wetting properties of beads and porous beads were characterized using this custom-designed setup. A small water droplet was placed directly on the surfaces and the contact angle was later calculated using image analysis (Fig. 3D2). Bare beads exhibit hydrophilic behavior which is consistent with silicon oxide terminated surfaces. The hydrophilic nature of the bead resulted in adhesion of the bead to the water meniscus at the end of the needle (Fig. 3D3). In the case of porous beads, an increase in the water contact angle was observed, which is likely a result of air voids formed by the opened channels. Hydrophilic beads were used in the remaining part of the study. We would like to note that the surface wetting properties of beads can be easily tuned, thanks to the versatile silicon oxide chemistry. Vapor-phase deposition of a fluoroalkyltrichlorosilane [30] makes the surface of beads hydrophobic, with a water contact angle of $109^{\circ}$ and $126^{\circ}$ for beads and porous beads, respectively (Fig. S6, Table S2, Supporting Information). The water contact angles of the beads can be further increased above $150^{\circ}$, a commonly accepted threshold used to define superhydrophobic surfaces [31]. For this purpose, the surface of beads was modified with an alkyl silane. Silica nanoparticles provided additional texture and made the surface of beads superhydrophobic. The porous beads exhibited higher water contact angles approaching $160^{\circ}$, as a result of additional texture provided by the open-ends of the channels. This study showed that surface wetting properties of beads and porous beads can be tailored as hydrophilic, hydrophobic and superhydrophobic. This versatility can be utilized according to the needs of a particular application.

\subsection{In vitro bioactivity test}

Fig. 4A shows FT-IR spectra of original beads and porous beads after soaking in SBF for up to 21 days. No significant changes were seen in the spectra of any beads after 14 days of soaking in SBF. However, two new bands at $\sim 560 \mathrm{~cm}^{-1}$ and $\sim 604 \mathrm{~cm}^{-1}$ (assigned to the $\mathrm{P}-\mathrm{O}$ bending vibrations in tetrahedral $\left[\mathrm{PO}_{4}\right]$ ) could be observed in the FT-IR spectra of porous beads after soaking in SBF for 21 day, but these bands were not observed in the spectrum of original beads [32]. Although
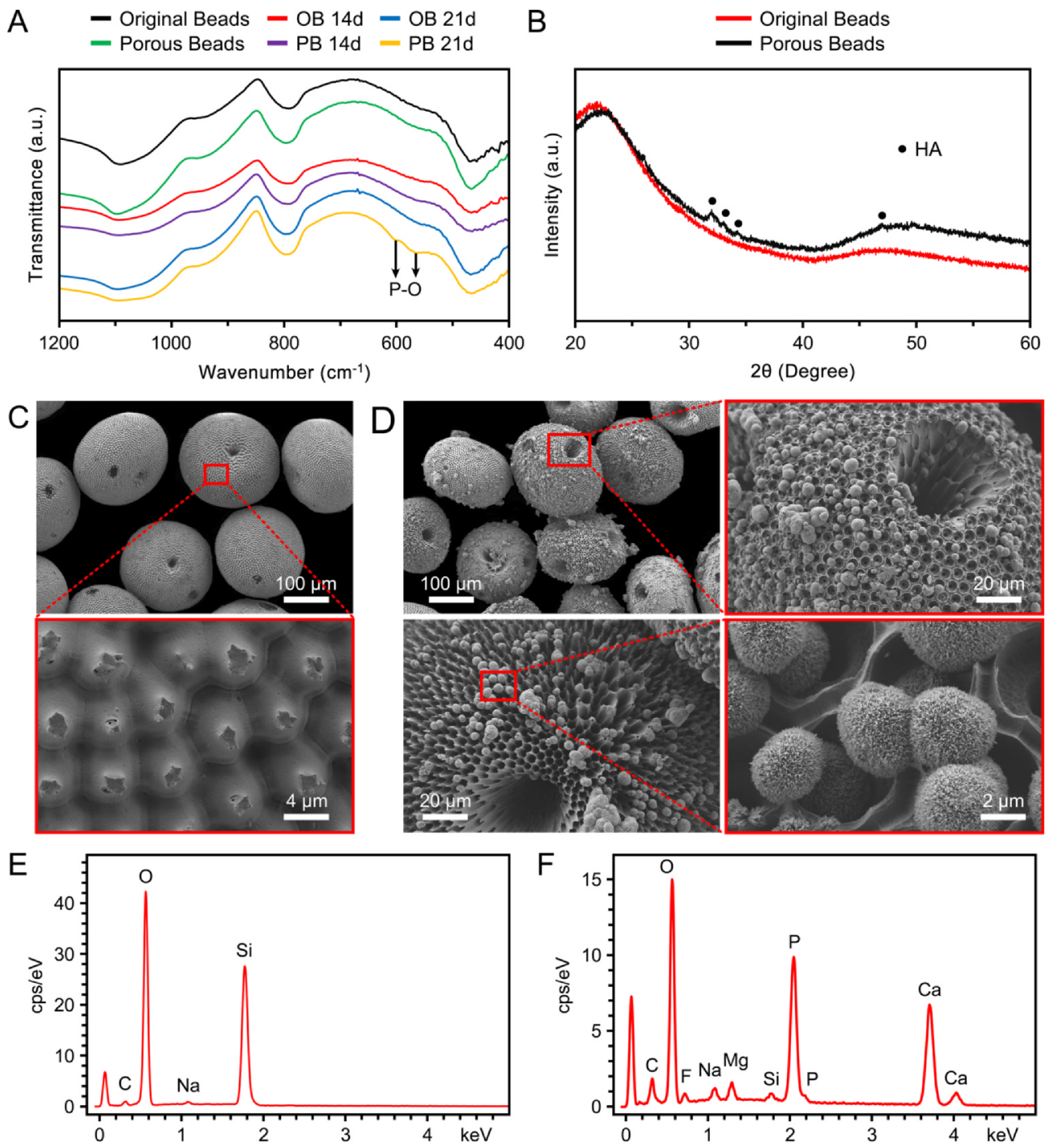

Fig. 4. Bioactivity test of original and porous beads. (A) FT-IR spectra after 14 and 21 days. (B) XRD results after 21 days. (C) SEM images of original beads after storage in SBF for 21 days. (D) SEM images of porous beads after storage in SBF for 21 days. The formed HA crystals (JCPDS 84-1998) are visible on the surface of the beads. (E) EDS of original beads after storage in SBF for 21 days. (F) EDS of porous beads after storage in SBF for 21 days. 
these two bands did not directly indicate the formation of hydroxyapatite, they suggested the presence of orthophosphate lattices that are well recognized as an indicator of hydroxyapatite. XRD patterns of these beads after soaking in SBF for 21 day confirmed the formation of $\mathrm{HA}$ in the porous beads as indicated by the observation of diffraction peaks located at $\sim 32^{\circ}, 33^{\circ}, 34^{\circ}$ and $48^{\circ}$ that are related to (211) (300) (202) and (312) crystallographic planes of HA (ICDD PDF 2 01-0894405) (Fig. 4B) [33]. However, no diffraction peaks were seen in the original beads indicating their amorphous nature, which was in agreement with the results of FT-IR. Fig. 4C and D shows SEM images of both beads after soaking in SBF for 21 days. The morphology of original beads remained similar to that of non-soaked beads. However, cauliflower-like clusters composed of needle-like crystals could be seen on porous beads, which were characteristic morphology of HA forming on the surface of bioactive materials after exposure to SBF. EDS results showed the deposition of phosphorus and the increase of Ca content in porous beads after soaking in SBF, indicating the formation of calcium phosphate species (Fig. 4E and F). However, this phenomenon was not observed in the original beads. In addition, the $\mathrm{Ca} / \mathrm{P}$ molar ratio of the porous beads was 1.57 , which is close to stoichiometric $\mathrm{Ca} / \mathrm{P}$ molar ratio of HA. This also proved the formation of HA. The experimental results indicated HA formation on the porous beads during the soaking in SBF, that leads to their bioactivity and potential use in bone regeneration applications.

It is well-agreed in the literature that the porous biosilica structures enhance the HA formation on silica surface and consequently increasing the bioactivity of bioglass. The underlying mechanism behind this phenomenon can be defined as the presence of a high number of silanol groups and high surface area available for SBF contact. As per literature reports, the bioglass exhibited the capacity to form apatite when soaked in SBF which is attributed to the nanoporous structure and to the presence of abundant silanol groups [34]. In the current case, we also hypothesize that after removal of the outermost layers two changes occur. 1) Higher number of silanol groups become available to chemically interact with SBF and form the HA. 2) Unearthing the pores and cavities of the bioglass beads offered a large surface area resulting in enhanced contact of SBF with bioglass. This large surface area favors the formation of HA in porous bioglass beads. On the other hand, the
A

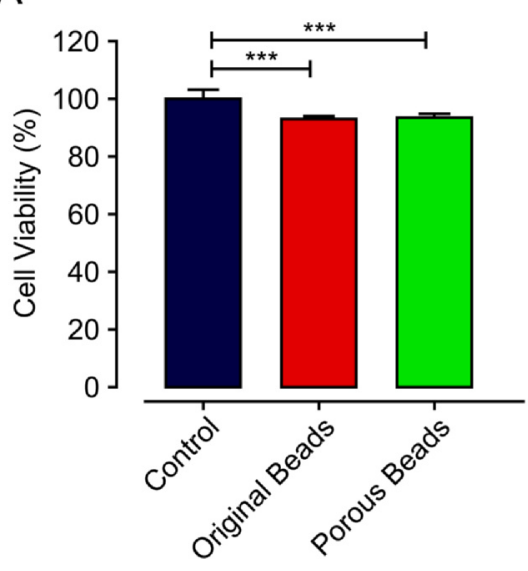

Samples

B

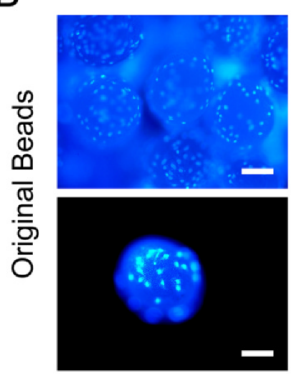

\section{D}

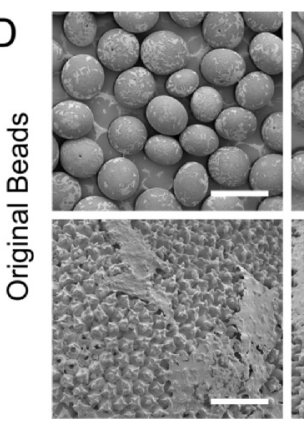

$48 \mathrm{~h}$
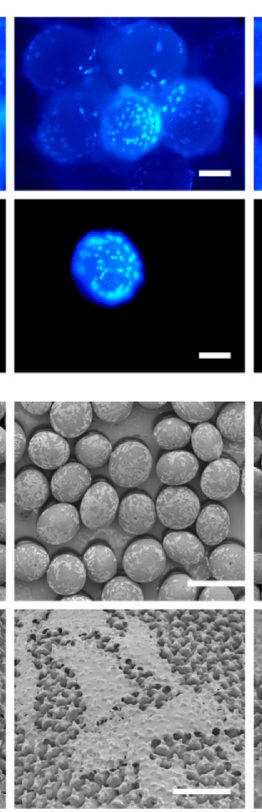

48h HOB WST-1

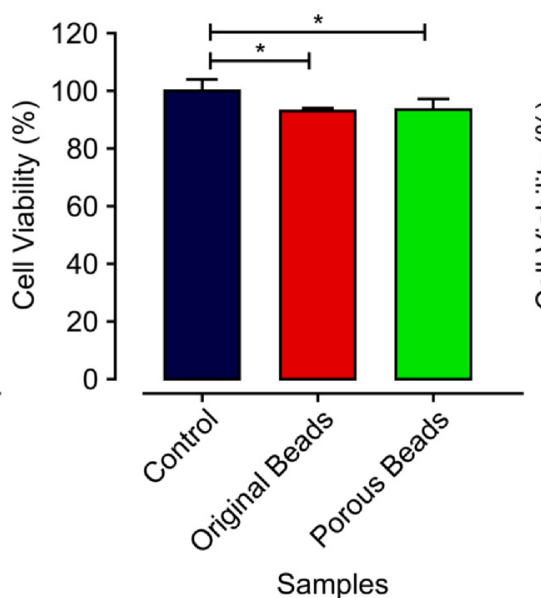

$72 \mathrm{~h}$

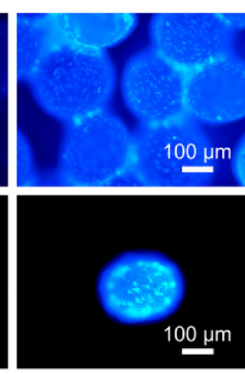

C
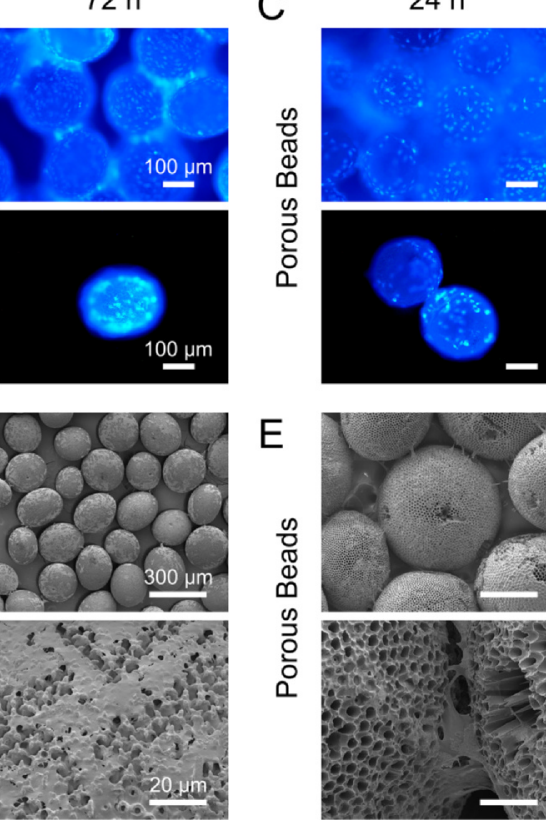

E

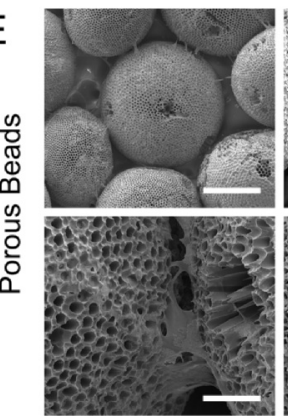

72h HOB WST-1

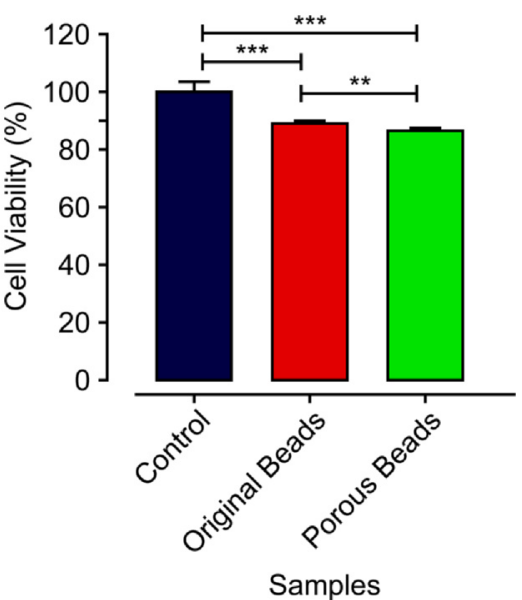

$48 \mathrm{~h}$

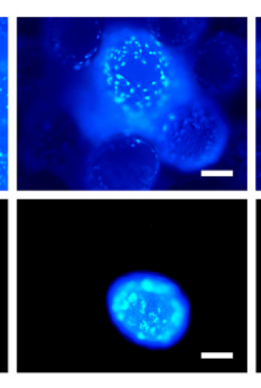

$72 \mathrm{~h}$
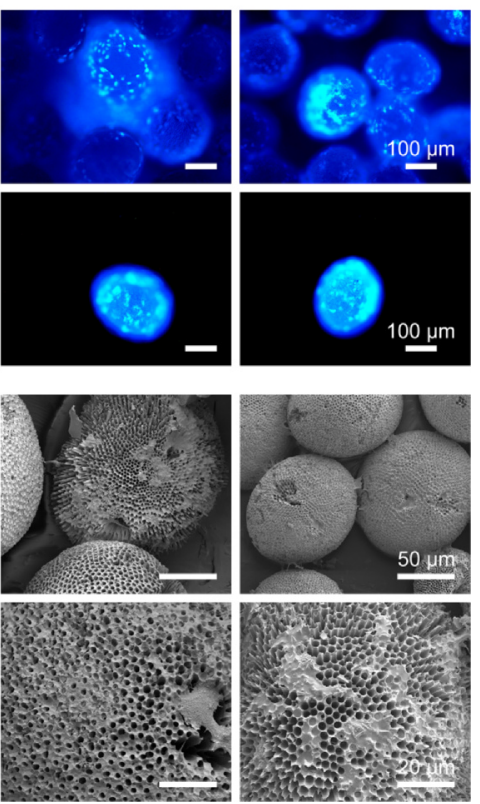

Fig. 5. (A) Cell viability results of HOB cells after being cultivated with bioglass beads for 24,48 and $72 \mathrm{~h}$. ( $p$-value below 0.05 is represented as; * for 0.01 to 0.05 , ** for 0.001 to 0.01 and $* * ;<0.001$ ). (B) and (C) Fluorescence microscopy images of DAPI stained HOB cells after being cultivated with spheres for $72 \mathrm{~h}$. (D) SEM images of the sterrasters and $(\mathrm{E})$ the porous biosilica beads. 
non-porous beads fail to offer enough silanol groups or contact area for SBF that leads to low or no HA formation $[34,35]$.

\subsection{Cell culture applications}

Proliferation and cell viability results of HOB cells that were incubated with micro glass spheres for 24 to $72 \mathrm{~h}$ were estimated with WST-1 cell proliferation test. Viability of cells for control (without any beads), original beads (micro glass spheres without pores) and bioglass beads with pores were recorded as $100 \%, 92.16 \%$ and $92.96 \%$. After $48 \mathrm{~h}$ of incubation viability of samples was recorded as $100 \%, 93.00 \%$ and $92.62 \%$. Viability of the cells changed to $100 \%, 90.42 \%$ and $86.83 \%$ at the end of $72 \mathrm{~h}$ (Fig. 5A). No cytotoxicity was observed on cells. Fluorescence microscopy visualization of stained cells on bioglass was performed with by Leica DM LB2, (Leica Microsystems, and Wetzlar, Germany) and images were captured with IM50. DAPI stained cell nuclei after $24 \mathrm{~h}$ and $72 \mathrm{~h}$ incubation with scaffolds were indicated in Fig. 5B and C. Nuclei of DAPI stained cells can be seen on microporous spheres indicating that cells liked and attached on those surfaces. SEM images of the cells can be seen in Fig. 5D and E. Porous spheres showed dense cellular bridges between them, and it can be concluded that cellular attachment on those surfaces makes them strong candidates for osteoblast friendly materials for different applications.

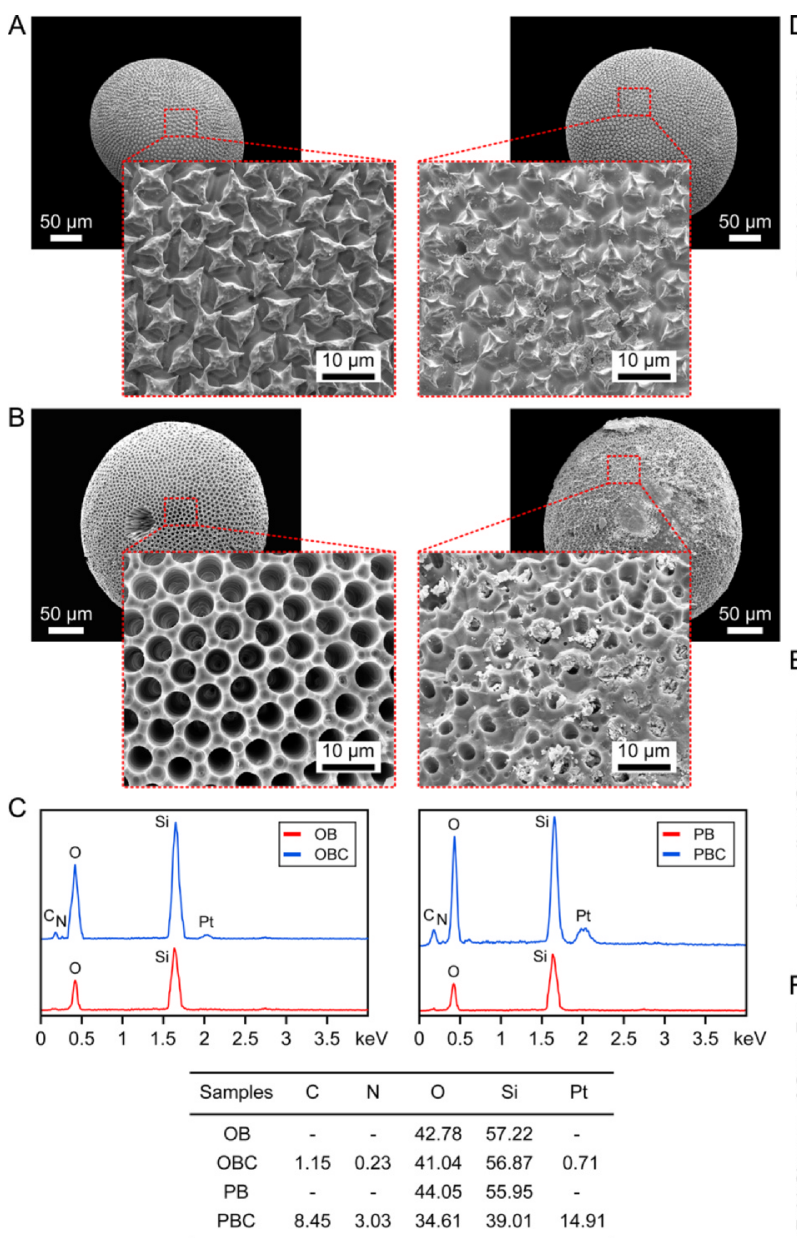

\subsection{Drug loading and releasing}

According to experimental studies, hydrophilic drug Carboplatin was successfully loaded into the beads. The loading capacity of the porous beads and non-treated beads were determined to be $10.59 \%$ and $0.96 \%$, respectively. SEM micrographs of original and porous beads before/after carboplatin loading are given in Fig. 6A and B, respectively. When EDS data from these images were compared, it can be seen that carboplatin loading of the porous beads is significantly larger (Fig. 6C). The carboplatin indicative platinum, carbon and nitrogen weight ratio were $14.91 \%, 8.45 \%$ and $3.03 \%$, respectively, for the porous beads whereas they were only $0.71 \%, 1.15 \%$ and $0.23 \%$, for the original non-porous beads. The SEM images show the surface adsorbed carboplatin in both cases.

Also, in the present study, the beads were used as a pH-sensitive carrier for carboplatin release. Therefore, in vitro cumulative release studies of the carboplatin loaded beads and the Carboplatin were carried out in $\mathrm{pH} 7.4$ and $\mathrm{pH} 5.0$ for examination of $\mathrm{pH}$ effect. The release profiles of the Carboplatin loaded beads and the carboplatin are shown in Fig. $6 \mathrm{D}$ for $120 \mathrm{~h}$ at $\mathrm{pH}=7.4$ and $\mathrm{pH}=5.0$, respectively. For $\mathrm{pH}=7.4$, maximum release of Carboplatin from the beads was $20.11 \%$ and the pure Carboplatin release was $40.29 \%$ at the end of the $4 \mathrm{~h}$, respectively. The burst release effect was observed for carboplatin release from the beads at $\mathrm{pH}=5.0$. The burst release is most likely untrapped on the beads surface or loosely entrapped Carboplatin into the beads. The initial fast release of carboplatin from the porous beads
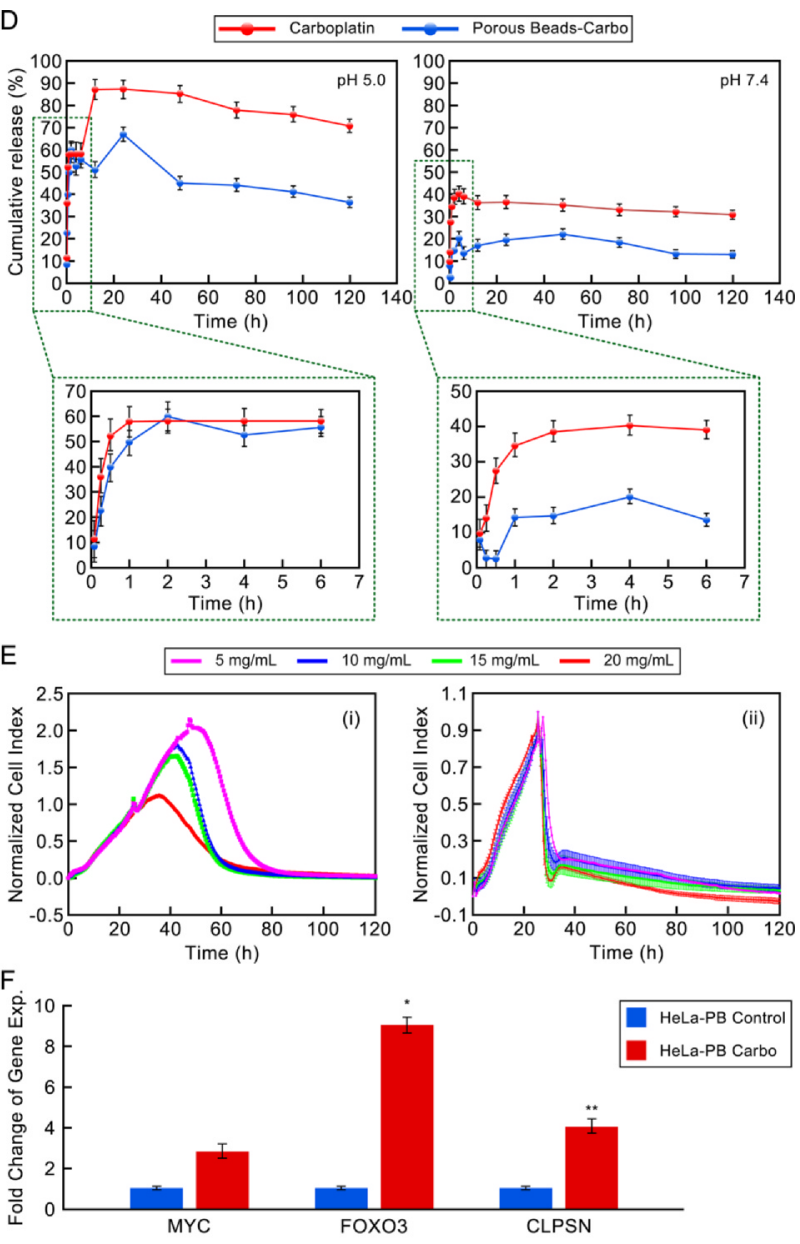

Fig. 6. (A) SEM images of unloaded (left) and Carboplatin loaded (right) original bead (sterraster). (B) SEM images of unloaded (left) and Carboplatin loaded (right) porous biosilica bead. (C) EDS results of porous biosilica bead and carboplatin loaded porous biosilica bead. (D) In vitro drug releasing at pH 5.0 and 7.4. Error bars denote standard deviation of 3 experiments. (E) Anti-proliferative effect of Carboplatin against HeLa cells (left) and anti-proliferative effect of the control drug against HeLa cells (right). (F) Fold change in the expression of significantly altered (porous biosilica beads) on HeLa cell (* $\mathrm{p}<0.05$; ${ }^{* *} \mathrm{p}<0.01$ ). 
could be attributed to the diffusion of the drug molecules, considering the water solubility of carboplatin. This phase is followed by a controlled-release phase. The controlled release rate can be due to the dissolution of the drug entrapped inside of the pores of the beads. For $\mathrm{pH}=5.0$, the maximum release of carboplatin from the beads was $66.97 \%$ and the pure carboplatin release was $87.29 \%$ at $24 \mathrm{~h}$, respectively. In vitro release studies clearly demonstrated that the Carboplatin release rates from beads decreased for both $\mathrm{pHs}$, when compared to pure carboplatin release.

\subsubsection{Real time cell analyzer (RTCA) aided anti-proliferative assay: slow} release by sponge sterrasters in cell culture

Bio-based carriers for the delivery and slow release of chemotherapeutic drugs have been widely introduced as a novel therapeutic approach in cancer therapy. Despite potent routine used cancer drugs, its clinical application has been limited because of drug resistance, toxic effect and poor bioavailability. Extended release drug delivery minimizes adverse side effects in cancer patients and enables the higher therapeutic potential to be achieved by prolonged drug release using steady-rate release or controlled release. In this study, the newly isolated sponge sterrasters were demonstrated as a potential novel drug carrying material for determination of effect on HeLa cell. The antiproliferative effect of Carboplatin loaded sponge sterrasters was evaluated by using real time cell analyzer system (Xcelligence).

Real time cell analyzer results showed significant antiproliferative effect with extended drug release by Carboplatin loaded porous biosilica bead (Fig. 6Ei) compared to the control (non-encapsulated free carboplatin) in HeLa cell culture (Fig. 6Eii). As shown in Fig. 6E, the $\mathrm{IC}_{50}$ values for Carboplatin loaded porous biosilica bead was calculated as $5 \mathrm{mg} / \mathrm{ml}$ for HeLa cells. Results revealed extended drug release pattern for Carboplatin loaded porous biosilica beads which lasted for $36 \mathrm{~h}$, while for the control this time period was around $3 \mathrm{~h}$. Free Carboplatin completely stopped the proliferation of HeLa cell in $3 \mathrm{~h}$ (Fig. 6Eii). Thus, porous biosilica beads emerges as an effective drug carrier with successful slow release ability. In the current study xCELLigence real-time cell analysis system was also used for the first time, which provides valuable information about behavior of the cells with hydroxycarbomide in a time-dependent process.

\subsubsection{Quantitative real-time RT-PCR}

To investigate the effect of slow release of carboplatin in HeLa cells in terms of apoptosis reference genes MYC, CLSPN and FOXO3 were selected and their expression levels were analyzed in tested samples by using qRT-PCR. The results demonstrated a significant increase in the expression levels of MYC, CLSPN, and FOXO3 genes in HeLa cells treated with Carboplatin loaded porous biosilica beads. As shown in Fig. 6F, when comparing the Carboplatin loaded beads with the control, the changes in the detected genes exhibited a significant increase $(p<0.05$ and $p<0.01)$. The gene expression results suggested that an extended-release carboplatin therapeutic strategy can cause HeLa cell death through the apoptotic pathway.

\section{Discussion}

The sponge spicules can be termed as a material of interest for bone tissue applications, thanks to its sophisticated structural and chemical composition. But so far, the studies have only been focused on spicules such as monaxons, triaxons, tetraxons and polyaxons. Moreover, the production of bioactive bioceramics at higher temperatures using spicule structures is also one of the most preferred topics of researchers in the field of biosilica $[14,36]$. Our study presents a paradigm shift by exploitation of naturally assembled GMS microbeads with sophisticated structure for bone tissue and drug delivery applications. So far, a very limited number of studies have reported the isolation of biosilica from sponge species for applications such as bone tissue engineering and drug release. These studies have mainly focused on spicules of different morphologies for osteoinduction and tissue engineering applications. The isolated biosilica was applied either as a template or as a raw material to design suitable biosilica based scaffolds using 3D printing or other additive manufacturing technologies. This issue not only increases the production cost but also leads to changes in the innate characteristics of the natural basilica. Barros, Aroso, Silva, Mano, Duarte and Reis [36] prepared silica-based surface-modified bioceramics from the marine sponge with induced hydroxyapatite formation through sintering at high temperature $\left(750^{\circ} \mathrm{C}\right)$. The surface modification was carried out through potassium hydroxide (KOH) and hydrochloric acid. However, in the current study bioactive silica bead were isolated with fine pores using a simple and low-cost isolation protocol. It is well evident from the literature that so far no study have mentioned the direct application of bioactive microbeads from sponges with fine pore geometry in drug delivery and bone tissue engineering. On the contrary, many researchers have focused on disk like silica structures from diatomite reporting its full physicochemical characterizations and possible applications in biomedicine. In addition, this is the first study reporting the isolation of biosilica from $G$. macandrewii specie of demosponges. A unique biosilica structure is discovered in sterraster spicules of Geodia genus. This unique biosilica morphology has been revealed through a hydrogen fluoride aided etching of the uppermost surface layer of oval spicule structures (sterraster) from G. macandrewii sponge. Unlike the earlier studies, herein the produced porous beads were observed as bioactive and biocompatible without any thermal or ceramization treatments.

Synthetic composite micro bead structures consisting of poly (lactic acid-glycolic acid) (PLGA) and silica have shown to be effective on growth of bone tissue $[37,38]$. However, the surface of those synthetic beads were nonporous. In recent years some researchers attempted to synthetically produce porous scaffold architecture by emulating nature's design and fabricate bioactive glass scaffolds [39-43]. The authors adopted a method based on direct-ink-write assembly of a hydrogelbased ink. However, as the authors stated, it was extremely hard to replicate natural architecture regarding outstanding mechanical properties of natural porous products [44]. In another study, chitosancoated porous polycaprolactone/bioactive glass nanocomposite scaffold was designed as substitute for natural bone composite [45]. There are tremendous advances in the area of fabrication of bioactive glass/ ceramic structures for tissue engineering applications but as clearly addressed in a recent review by Baino, Fiume, Barberi, Kargozar, Marchi, Massera and Verné [46] synthetically designed porous structures have serious drawbacks such as process reproducibility and capability to fabricate large and complex porous bodies and difficulty in controlling pore geometry [46]. Considering the difficulty in standardization, high cost and labor in the production of synthetic micro beads, it is crucial that the porous micro beads prepared in the current work are already perfected since they are naturally designed as a structural part of a living organism existing for millions of years. In addition to these features, porous biosilica beads exhibit a unique feature; the pores on the surface exhibits the openings of the perfectly designed channel systems leading into a hollow core inside the porous biosilica beads. More interestingly, the dead bodies of this sponge species accumulate at the bottom of the ocean and remain intact for many years without their structure being disrupted. It has been noted that the shell of the sponge consists of more than $60 \%$ sterraster content in dry weight. The discussion here shows that the availability of the sponges will not be a limitation if the sponges are harvested for production of porous micro beads. Therefore, the commercialization potential of the porous micro beads is high.

Bioactive silicate glasses are biodegradable, biocompatible, osteoconductive and osteoinductive. It is known to attract osteoprogenitor cells to proliferate, differentiate and form bone organic matrix on it through the silica gel layer [16,47]. Schröder, Boreiko [48] investigated the effect of silicatein enzyme derived biosilica coated plates on calcium phosphate formation by human osteosarcoma (SaOS-2) cells via alizarin 
red -S staining in vitro. Increased calcium mineral contents on coated surfaces were observed together with increased cell viability. In another study on Aplysina fulva derived marine spongin (SPG) and biosilicate ${ }^{\circledR}$ (BS) scaffolds were manufactured. Mouse calvaria derived MC3T3-E1 sub clone 14 preosteoblastic cells and murine fibroblast cells (L929) were seeded onto scaffolds and BS dependent viability increase was observed on L929 cells at the day 7. No significant ALP activity difference was observed between BS and BS/SPG scaffolds, and BS/SPG scaffolds showed increased MC3T3 viability at day 7 [49]. In the light of the current literature information, it can be concluded that microporous spheres can be strong candidates with their high viability (above $86 \%$ ), biocompatibility and cellular adhesion friendly surfaces that promote bone regeneration and growth and open new application fields in bone tissue engineering.

For drug delivery applications, a single large administration dose of drugs causes the undesirable effects; i) increase of the toxic side effects, ii) quick drops below the minimum effective concentration, iii) decrease of the bioavailability. Therefore, it is attractive to develop new drug carriers for providing the controlled and targeted drug release. For this purpose, several drug carriers such as dendrimer, liposomes, carbon nano-tubes, biodegradable polymers and silica-based materials have been developed to increase of the therapeutic efficacy of a drug. Among them, silica based drug carriers have gained increasing interest due to their porous structures, functional surfaces, tunable pores, structural, thermal and chemical stability [50]. The silica-based materials used as drug carriers have been synthesized chemically. However, in the present study, a porous silica-based carrier was biologically (naturally) synthesized to be used for the Carboplatin release.

Although the capacity of the passive loading technique was limited, this result is close to the loading capacity of chitosan [51]. Also, the PLGA nanoparticles were used as a drug carrier for Carboplatin in the study of Sadhukka and Prabha [52]. The encapsulation efficiency was found to be $1.5 \%$ and $3.9 \%$ according to two preparation protocols of Sadhukka and Prabha. In the present study, the loading capacity of the Carboplatin into the beads was higher than that of the PLGA nanoparticles. The reason behind the higher loading capacity than the PLGA nanoparticles can be due to the comparatively high interaction between the carboplatin and beads. Also the release of the loaded drugs into the carriers are significant, so the release of the drugs is controlled by several stimuli such as ionic strength, temperature, $\mathrm{pH}$ and electrical or magnetic fields [53]. It is possible in stimulus-controlled release that the carriers have been investigated as the targeted drug delivery. Especially, the $\mathrm{pH}$ dependent release carriers have been developed as tumor-targeted drug carriers due to the weakly acidic nature of solid tumors [54-56]. In the present study, the results suggested that the beads exhibited a pH-dependent release. In vitro release studies revealed that the beads could be used as a convenient material for drug delivery systems for cancer drugs. The results demonstrated that the porous beads provide a system of low release rate and a well barrier against the drug diffusion under the different $\mathrm{pH}$ conditions. These results proved that the beads could be a pH-responsive drug delivery vehicle, which is minimizing the drug loss caused by $\mathrm{pH}$ in the physiologically normal cells. When the beads arrive to the tumor cells with $\mathrm{pH}$ (5.0), they initiated the fast-anticancer drug release. In this regard, we checked its releasing effect on human HeLa cancer cells and the results demonstrated that the Carboplatin loaded beads significantly suppressed cell proliferation owing to drug release over a prolonged period and promoted the induction of apoptosis. Extended-release of Carboplatin delivery from biosilica beads can overcome the negative effect of routine used cancer drug on patients and it might be regarded as an attractive therapeutic option for cancer therapy.

\section{Conclusion}

In summary, novel porous biosilica based beads with interesting surface features were isolated from a marine sponge (Geodia macandrewii) using a simple low-cost extraction technique. Detailed physicochemical and biological properties of the new isolate were obtained. Surface analysis revealed a unique morphology of biosilica beads (which was unveiled after HF treatment) that is multiple channels opening to a hollow cavity. The physicochemical and biological properties (especially nontoxicity) of the isolates inspired further bioactivity assays for potential use of the beads in osteogenic applications. Bioactivity results revealed a hydroxyapatite formation over the surface of newly isolated biosilica beads. Besides, the hollow channels opening to a central cavity favors the use of the biosilica beads as controlled cargo release carriers for anticancer drugs. GMS beads showed excellent performance as drug carriers both in simulated and in cell culture conditions. Considering the current results, the produced multifunctional silica-based porous microbeads can find many application areas in different fields, thanks to its negatively charged surface and sophisticated interconnected structural geometry. These applications include adsorption/absorption of different biomolecules, such as proteins, growth factors, DNA/RNA for biosensing and chromatography as well as dye removal processes and energy storage.

\section{Declaration of Competing Interest}

The authors declare that they have no known competing financial interests or personal relationships that could have appeared to influence the work reported in this paper.

\section{Acknowledgements}

Thanks to ASUBTAM (Aksaray University) and National Nanotechnology Research Center (UNAM) for providing laboratory facilities and access to equipment.

\section{Appendix A. Supplementary data}

Supplementary data to this article can be found online at https:// doi.org/10.1016/j.cej.2020.126667.

\section{References}

[1] J. Zhang, D. Xiao, X. He, F. Shi, P. Luo, W. Zhi, K. Duan, J. Weng, A novel porous bioceramic scaffold by accumulating hydroxyapatite spheres for large bone tissue engineering. III: characterization of porous structure, Mater. Sci. Eng., C 89 (2018) 223-229.

[2] T. Agarwal, P. Kabiraj, G.H. Narayana, S. Kulanthaivel, U. Kasiviswanathan, K. Pal, S. Giri, T.K. Maiti, I. Banerjee, Alginate bead based hexagonal close packed 3D implant for bone tissue engineering, ACS Appl. Mater. Interfaces 8 (2016) $32132-32145$.

[3] H.Y. Kim, J.H. Lee, J.-W. Yun, J.-H. Park, B.-W. Park, G.-J. Rho, S.-J. Jang, J.S. Park, H.-C. Lee, Y.M. Yoon, Development of porous beads to provide regulated BMP-2 stimulation for varying durations: in vitro and in vivo studies for bone regeneration, Biomacromolecules 17 (2016) 1633-1642.

[4] S.E. Kim, Y.-P. Yun, K.-S. Shim, K. Park, S.-W. Choi, D.H. Shin, D.H. Suh, Fabrication of a BMP-2-immobilized porous microsphere modified by heparin for bone tissue engineering, Colloids Surf., B 134 (2015) 453-460.

[5] S. Ni, J. Chang, L. Chou, A novel bioactive porous CaSiO3 scaffold for bone tissue engineering, J. Biomed. Mater. Res. Part A 76 (2006) 196-205.

[6] C. Qi, Y.-J. Zhu, B.-Q. Lu, X.-Y. Zhao, J. Zhao, F. Chen, Hydroxyapatite nanosheetassembled porous hollow microspheres: DNA-templated hydrothermal synthesis, drug delivery and protein adsorption, J. Mater. Chem. 22 (2012) 22642-22650.

[7] C. Sharma, A.K. Dinda, P.D. Potdar, C.-F. Chou, N.C. Mishra, Fabrication and characterization of novel nano-biocomposite scaffold of chitosan-gelatin-alginate-hydroxyapatite for bone tissue engineering, Mater. Sci. Eng., C 64 (2016) 416-427.

[8] S. Tamburaci, F. Tihminlioglu, Biosilica incorporated 3D porous scaffolds for bone tissue engineering applications, Mater. Sci. Eng., C 91 (2018) 274-291.

[9] M. Wiens, X. Wang, F. Natalio, H.C. Schröder, U. Schloßmacher, S. Wang, M. Korzhev, W. Geurtsen, W.E. Müller, Bioinspired fabrication of bio-silica-based bone-substitution materials, Adv. Eng. Mater. 12 (2010) 438-450.

[10] W. Zhu, X. Gao, X. Zou, W.E. Müller, S. Wang, Y. Wang, Y. Liu, Biosilica porous microspheres promote the osteogenic/odontogenic differentiation of human dental pulp cells, J. Biomater. Tissue Eng. 8 (2018) 258-266.

[11] J. Guo, C. Li, S. Ling, W. Huang, Y. Chen, D.L. Kaplan, Multiscale design and synthesis of biomimetic gradient protein/biosilica composites for interfacial tissue 
engineering, Biomaterials 145 (2017) 44-55.

[12] M. Wiens, X. Wang, H.C. Schröder, U. Kolb, U. Schloßmacher, H. Ushijima, W.E. Müller, The role of biosilica in the osteoprotegerin/RANKL ratio in human osteoblast-like cells, Biomaterials 31 (2010) 7716-7725.

[13] M. Łukowiak, Late Eocene siliceous sponge fauna of southern Australia: reconstruction based on loose spicules record, Zootaxa 3917 (2015) 1-65.

[14] A.A. Barros, I.M. Aroso, T.H. Silva, J.F. Mano, A.R.C. Duarte, R.L. Reis, In vitro bioactivity studies of ceramic structures isolated from marine sponges, Biomed. Mater. 11 (2016) 045004.

[15] P. Gabbai-Armelin, H. Kido, M. Cruz, J. Prado, I. Avanzi, M. Custódio, A. Renno, R. Granito, Characterization and cytotoxicity evaluation of a marine sponge biosi lica, Mar. Biotechnol. 21 (2019) 65-75.

[16] R.N. Granito, M.R. Custodio, A.C.M. Rennó, Natural marine sponges for bone tissue engineering: the state of art and future perspectives, J. Biomed. Mater. Res. B Appl. Biomater. 105 (2017) 1717-1727.

[17] M. Jensen, R. Keding, T. Höche, Y. Yue, Biologically formed mesoporous amorphous silica, J. Am. Chem. Soc. 131 (2009) 2717-2721.

[18] P. Werner, H. Blumtritt, I. Zlotnikov, A. Graff, Y. Dauphin, P. Fratzl, Electron mi croscope analyses of the bio-silica basal spicule from the Monorhaphis chuni sponge, J. Struct. Biol. 191 (2015) 165-174.

[19] M. Inoue, Y. Iwasaki, A problematic micro-organism similar to the sterraster of sponges, Proc. Japan Acad. 51 (1975) 273-278.

[20] H. Lehnert, R.P. Stone, Two new species of Geodiidae (Porifera, Demospongiae, Astrophorina) from the Emperor Seamounts, North Pacific Ocean, Zootaxa 4671 (2019) 381-395.

[21] W.E. Müller, U. Schloßmacher, C. Eckert, A. Krasko, A. Boreiko, H. Ushijima, S.E. Wolf, W. Tremel, I.M. Müller, H.C. Schröder, Analysis of the axial filament in spicules of the demosponge Geodia cydonium: different silicatein composition in microscleres (asters) and megascleres (oxeas and triaenes), Eur. J. Cell Biol. 86 (2007) 473-487.

[22] K. Rützler, I.G. Macintyre, Siliceous sponge spicules in coral reef sediments, Mar. Biol. 49 (1978) 147-159.

[23] P. Cárdenas, J.A. Moore, First records of Geodia demosponges from the New England seamounts, an opportunity to test the use of DNA mini-barcodes on museum specimens, Mar. Biodivers. 49 (2019) 163-174.

[24] P. Cárdenas, H.T. Rapp, Demosponges from the Northern Mid-Atlantic Ridge shed more light on the diversity and biogeography of North Atlantic deep-sea sponges, J. Marine Biol. Assoc. U. K. 95 (2015) 1475-1516.

[25] T. Kokubo, H. Takadama, How useful is SBF in predicting in vivo bone bioactivity? Biomaterials 27 (2006) 2907-2915.

[26] T. Boulikas, M. Vougiouka, Recent clinical trials using cisplatin, carboplatin and their combination chemotherapy drugs, Oncol. Rep. 11 (2004) 559-595.

[27] J. Greeley, L. Meeuwenberg, M. Banaszak Holl, Surface infrared studies of silicon/ silicon oxide interfaces derived from hydridosilsesquioxane clusters, J. Am. Chem. Soc. 120 (1998) 7776-7782.

[28] R. Mueller, H.K. Kammler, K. Wegner, S.E. Pratsinis, OH surface density of SiO2 and TiO2 by thermogravimetric analysis, Langmuir 19 (2003) 160-165.

[29] M. Sprynskyy, P. Pomastowski, M. Hornowska, A. Król, K. Rafińska, B. Buszewski, Naturally organic functionalized 3D biosilica from diatom microalgae, Mater. Des. 132 (2017) 22-29.

[30] I. Torun, Y. Altintas, A.F. Yazici, E. Mutlugun, M.S. Onses, Solid-state encapsulation and color tuning in films of cesium lead halide perovskite nanocrystals for white light generation, ACS Appl. Nano Mater. 2 (2019) 1185-1193.

[31] C. Peng, Z. Chen, M.K. Tiwari, All-organic superhydrophobic coatings with mechanochemical robustness and liquid impalement resistance, Nat. Mater. 17 (2018) 355-360.

[32] K. Zheng, A. Solodovnyk, W. Li, O.M. Goudouri, C. Stähli, S.N. Nazhat, A.R. Boccaccini, Aging time and temperature effects on the structure and bioactivity of gel-derived 45 S5 glass-ceramics, J. Am. Ceram. Soc. 98 (2015) 30-38.

[33] P. Seredin, D. Goloshchapov, T. Prutskij, Y.A. Ippolitov, Fabrication and characterisation of composites materials similar optically and in composition to native dental tissues, Results Phys. 7 (2017) 1086-1094.

[34] C. Covarrubias, M. Mattmann, A. Von Marttens, P. Caviedes, C. Arriagada, F. Valenzuela, J.P. Rodríguez, C. Corral, Osseointegration properties of titanium dental implants modified with a nanostructured coating based on ordered porous silica and bioactive glass nanoparticles, Appl. Surf. Sci. 363 (2016) 286-295.

[35] D. Inzunza, C. Covarrubias, A.V. Marttens, Y. Leighton, J.C. Carvajal, F. Valenzuela, M. Díaz-Dosque, N. Mendez, C. Martínez, A.M. Pino, Synthesis of nanostructured porous silica coatings on titanium and their cell adhesive and osteogenic differentiation properties, J. Biomed. Mater. Res. Part A 102 (2014) 37-48.

[36] A.A. Barros, I.M. Aroso, T.H. Silva, J.F. Mano, A.R.C. Duarte, R.L. Reis, Surface modification of silica-based marine sponge bioceramics induce hydroxyapatite formation, Cryst. Growth Des. 14 (2014) 4545-4552.

[37] S. Wang, X. Wang, F.G. Draenert, O. Albert, H.C. Schröder, V. Mailänder, G. Mitov, W.E. Müiller, Bioactive and biodegradable silica biomaterial for bone regeneration, Bone 67 (2014) 292-304.

[38] W. Xu, L. Wang, Y. Ling, K. Wei, S. Zhong, Enhancement of compressive strength and cytocompatibility using apatite coated hexagonal mesoporous silica/poly (lactic acid-glycolic acid) microsphere scaffolds for bone tissue engineering, RSC Adv. 4 (2014) 13495-13501.

[39] E. Boccardi, L. Liverani, A.R. Boccaccini, Bioactive behavior of mesoporous silica particle (MCM-41) coated bioactive glass-based scaffolds, Int. J. Appl. Ceram. Technol. 16 (2019) 1753-1761.

[40] E. Boccardi, A. Philippart, V. Melli, L. Altomare, L. De Nardo, G. Novajra, C. VitaleBrovarone, T. Fey, A. Boccaccini, Bioactivity and mechanical stability of $45 \mathrm{~S} 5$ bioactive glass scaffolds based on natural marine sponges, Ann. Biomed. Eng. 44 (2016) 1881-1893.

[41] S. Ramlee, N. Sharifulden, H. Mohamad, S. Noor, Sol-gel derived bioactive glass scaffolds incorporated with polyvinyl-alcohol and pluronic P123 polymers using sponge replication technique, Mater. Today:. Proc. 17 (2019) 966-975.

[42] C. Vitale-Brovarone, F. Baino, E. Verné, High strength bioactive glass-ceramic scaffolds for bone regeneration, J. Mater. Sci. - Mater. Med. 20 (2009) 643-653.

[43] C. Wu, Y. Zhou, W. Fan, P. Han, J. Chang, J. Yuen, M. Zhang, Y. Xiao, Hypoxiamimicking mesoporous bioactive glass scaffolds with controllable cobalt ion release for bone tissue engineering, Biomaterials 33 (2012) 2076-2085.

[44] Q. Fu, E. Saiz, A.P. Tomsia, Bioinspired strong and highly porous glass scaffolds, Adv. Funct. Mater. 21 (2011) 1058-1063.

[45] M. Shaltooki, G. Dini, M. Mehdikhani, Fabrication of chitosan-coated porous polycaprolactone/strontium-substituted bioactive glass nanocomposite scaffold for bone tissue engineering, Mater. Sci. Eng., C 105 (2019) 110138.

[46] F. Baino, E. Fiume, J. Barberi, S. Kargozar, J. Marchi, J. Massera, E. Verné, Processing methods for making porous bioactive glass-based scaffolds-a state-ofthe-art review, Int. J. Appl. Ceram. Technol. 16 (2019) 1762-1796.

[47] H.C. Schröder, V.A. Grebenjuk, X. Wang, W.E. Müller, Hierarchical architecture of sponge spicules: biocatalytic and structure-directing activity of silicatein proteins as model for bioinspired applications, Bioinspiration Biomimetics 11 (2016) 041002.

[48] H.C. Schröder, O. Boreiko, A. Krasko, A. Reiber, H. Schwertner, W.E. Müller, Mineralization of SaOS-2 cells on enzymatically (silicatein) modified bioactive osteoblast-stimulating surfaces, J. Biomed. Mater. Res. B Appl. Biomater. 75 (2005) $387-392$.

[49] K. Fernandes, J. Parisi, A. Magri, H. Kido, P. Gabbai-Armelin, C. Fortulan, E. Zanotto, O. Peitl, R. Granito, A. Renno, Influence of the incorporation of marine spongin into a Biosilicate ${ }^{\oplus}$ : an in vitro study, J. Mater. Sci. - Mater. Med. 30 (2019) 64.

[50] W. Tan, K. Wang, X. He, X.J. Zhao, T. Drake, L. Wang, R.P. Bagwe, Bionanotechnology based on silica nanoparticles, Med. Res. Rev. 24 (2004) 621-638.

[51] M.A. Khan, M. Zafaryab, S.H. Mehdi, J. Quadri, M.M.A. Rizvi, Characterization and carboplatin loaded chitosan nanoparticles for the chemotherapy against breast cancer in vitro studies, Int. J. Biol. Macromol. 97 (2017) 115-122.

[52] T. Sadhukha, S. Prabha, Encapsulation in nanoparticles improves anti-cancer efficacy of carboplatin, Aaps Pharmscitech 15 (2014) 1029-1038.

[53] S.A. Abouelmagd, H. Hyun, Y. Yeo, Extracellularly activatable nanocarriers for drug delivery to tumors, Expert Opin. Drug Deliv. 11 (2014) 1601-1618.

[54] C.-C. Chang, J.-Y. Kuo, K.-K. Chen, A.-T.-L. Lin, Y.-H. Chang, H.H. Wu, L.S. Chang, Transurethral prostatic resection for acute urinary retention in patients with prostate cancer, J. Chinese Med. Assoc. 69 (2006) 21-25.

[55] K.H. Min, J.-H. Kim, S.M. Bae, H. Shin, M.S. Kim, S. Park, H. Lee, R.-W. Park, I.S. Kim, K. Kim, Tumoral acidic pH-responsive MPEG-poly ( $\beta$-amino ester) polymeric micelles for cancer targeting therapy, J. Control. Release 144 (2010) $259-266$

[56] M. Talelli, M. Iman, A.K. Varkouhi, C.J. Rijcken, R.M. Schiffelers, T. Etrych, K. Ulbrich, C.F. van Nostrum, T. Lammers, G. Storm, Core-crosslinked polymeric micelles with controlled release of covalently entrapped doxorubicin, Biomaterials 31 (2010) 7797-7804. 